agreement with the reaction: lactate ${ }^{-}+2 \mathrm{H}_{2} \mathrm{O}+2 \mathrm{AQDS} \rightarrow$ $2 \mathrm{AHDS}+$ acetate $^{-}+\mathrm{HCO}_{3}^{-}+\mathrm{H}^{+}$.

Technical difficulties prevented cell growth of $G$. metallireducens from being monitored with humic acids as the electron acceptor (Fig. 4); however, $S$. alga grew in a medium in which humic acids were the sole electron acceptor (Fig. 4c). Growth was associated with an accumulation of reducing potential in the humic acids that could be transferred to $\mathrm{Fe}$ (III) when $\mathrm{Fe}$ (III) was added to cell-free filtrates of the culture. Growth was not due to degradation by $S$. alga of humic acids because there was no growth in the presence of humic acids if lactate, the electron donor, was omitted (Fig. 4c). These results show that respiration with humic acids as the terminal electron acceptor can yield energy to support cell growth.

Besides revealing a new form of microbial respiration, these findings may have important implications for the biogeochemistry of soils and aquatic sediments. For example, the reduction of insoluble $\mathrm{Fe}$ (III) and $\mathrm{Mn}$ (IV) oxides is one of the most geochemically significant processes that takes place in sedimentary environments $^{18,19}$. Previous investigations into the mechanisms for the reduction of $\mathrm{Fe}(\mathrm{III})$ and $\mathrm{Mn}$ (IV) have emphasized either the abiological reduction of these metals by organics such as humic materials and related aromatic compounds ${ }^{20}$, or the direct biological reduction of the metals by specialized metal-reducing microorganisms ${ }^{21}$. Our results suggest that, at least in some instances, the reduction of $\mathrm{Fe}$ (III) (and other metals such as Mn(IV) that can also accept electrons from humic substances) may actually be a combination of both processes, with microorganisms first donating electrons to humic substances and the humic substances then reducing the metals. Such electron shuttling may greatly facilitate the ability of $\mathrm{Fe}$ (III)-reducing bacteria to pass electrons to insoluble $\mathrm{Fe}$ (III) oxides and is the likely explanation for the earlier observation ${ }^{2}$ that humic acids greatly accelerate the rate of benzene degradation in aquifer sediments in which $\mathrm{Fe}$ (III) is the terminal electron acceptor. Even when $\mathrm{Fe}$ (III) is not available to recycle humic substances back to their oxidized form, humic substances may still be important electron acceptors for organic matter oxidation, given the abundance of humic substances in many soils and sediments. The known ability of reduced humic acids to donate electrons to a variety of metals and organics ${ }^{6,9,10,12}$ suggests that microbial reduction of humic acids may have an impact on the fate of other environmental contaminants as well.

Received 7 May; accepted 14 June 1996.

1. McKnight, D. M. et al. in Organic Acids in Aquatic Ecosystems (eds Perdue, E. M. \& Gjessing, E. T.) 223-243 (Wiley, New York, 1990).

2. Lovley, D. R., Woodward, J. C. \& Chapelle, F. H. Appl. environ. Microbiol. 62, 288-291 (1996).

3. Lovley, D. R., Woodward, J. C. \& Chapelle, F. H. Nature 370, 128-131 (1994).

4. Lovley, D. R. \& Woodward, J. C. Chem. Geol. (in the press).

5. Jackson, K. S., Jonasson, I. R. \& Skippen, G. B. Earth Sci. Rev. 14, 97-146 (1978).

6. Alberts, J. J., Schindler, J. E., Miller, R. W. \& Nutter, D. E. Science 184, 895-897 (1974).

7. Schindler, J. E., Williams, D. J. \& Zimmerman, A. P. in Environmental Biogeochemistry Vol. 1 (eds Nriagu, J. O.) 109-115 (Ann Arbor Science, Ann Arbor, Michigan, 1976).

8. Schwarzenbach, R. P., Stierli, R., Lanz, K. \& Zeyer, J. Environ. Sci. Technol. 24, 1566-1574 (1990).

9. Dunnivant, F. M., Schwarzenbach, R. P. \& Macalady, D. L. Environ. Sci. Technol. 26, 21332142 (1992).

10. Curtis, C. P. \& Reinhard, M. Environ. Sci. Technol. 28, 2393-2401 (1994).

11. Szilagyi, M. Soil Sci. 111, 233-235 (1971).

12. Skogerboe, R. K. \& Wilson, S. A. Analyt. Chem. 53, 228-232 (1981).

13. Kahn, T. R. Langford, C. H. \& Skippen, G. B. Org. Geochem. 7, 261-266 (1984).

14. Lovley, D. R. \& Phillips, E. J. P. Appl. environ. Microbiol. 54, 1472-1480 (1988).

15. Caccavo, F. Jr, Blakemore, R. P. \& Lovley, D. R. Appl. environ. Microbiol. 58, 3211-3216 (1992).

16. Rossello-Mora, R. A. et al. Syst. appl. Microbiol. 17, 569-573 (1994).

17. Tratnyek, P. G. \& Macalady, D. L. J. Agricul. Food Chem. 37, 248-254 (1989).

18. Ponnamperuma, F. N. Adv. Agron. 24, 29-96 (1972).

19. Lovley, D. R. Adv. Agron. 54, 175-231 (1995)

20. LaKind, J. S. \& Stone, A. T. Geochim. cosmochim. Acta 53, 961-971 (1989).

21. Lovley, D. R., Phillips, E. J. P. \& Lonergan, D. J. Environ. Sci. Technol. 25, 1062-1067 (1991). 22. Lovley, D. R. \& Phillips, E. J. P. Appl. Environ. Microbiol. 51, 683-689 (1986).

ACKNOWLEDGEMENTS. We thank D. McKnight and P. Tratnyek for helpful discussions. This research was supported by the Office of Naval Research and by the American Petroleum Institute.

CORRESPONDENCE and requests for materials should be addressed to D.R.L. (e-mail: dlovley@ microbio.umass.edu).

\section{Increased bone formation in osteocalcin-deficient mice}

\author{
Patricia Ducy, Christelle Desbois, Brendan Boyce*, \\ Gerald Pinero $\dagger$, Beryl Story*, Colin Dunstan $\ddagger$, \\ Erica Smith§, Jeffrey Bonadio\|, Steven Goldstein§, \\ Caren Gundbergף, Allan Bradley\# \& Gerard Karsenty
}

Department of Molecular Genetics, The University of Texas M.D. Anderson Cancer Center, 1515 Holcombe Blvd, Box 45, Houston, Texas 77030 , USA Departments of * Pathology, and $\ddagger$ Medicine, The University of Texas Health Science Center, San Antonio, Texas 78284, USA

$\dagger$ Department of Basic Science, Dental Branch University of Texas, Houston, Texas 77030, USA

Departments of $\S$ Orthopaedics, and \| Pathology, University of Michigan

Medical School, Ann Arbor, Michigan 48109, USA

T Department of Orthopaedics, Yale School of Medicine, New Haven, Connecticut 06510, USA

\# Howard Hughes Medical Institute and Department of Molecular and Human Genetics, Baylor College of Medicine, Houston, Texas 77030, USA

VERTEBRATES constantly remodel bone. The resorption of preexisting bone by osteoclasts and the formation of new bone by osteoblasts is strictly coordinated to maintain bone mass within defined limits. A few molecular determinants of bone remodelling that affect osteoclast activity ${ }^{1-3}$ have been characterized, but the molecular determinants of osteoblast activity are unknown. To investigate the role of osteocalcin, the most abundant osteoblast-specific non-collagenous protein ${ }^{4}$, we have gen- erated osteocalcin-deficient mice. These mice develop a phenotype marked by higher bone mass and bones of improved functional quality. Histomorphometric studies done before and after ovariectomy showed that the absence of osteocalcin leads to an increase in bone formation without impairing bone resorption. To our knowledge, this study provides the first evidence that osteocalcin is a determinant of bone formation.

Osteocalcin, the most abundant non-collagenous protein (NCP) of the bone extracellular matrix (ECM), is synthesized only by osteoblasts ${ }^{5,6}$. The mouse osteocalcin cluster contains three genes, two of which (OG1 and $O G 2)$ encode osteocalcin. Their coding sequences are $96 \%$ identical, and they are expressed only by osteoblasts, whereas the third gene, osteocalcin-related gene $(O R G)$, is expressed in kidney but not in bone ${ }^{7}$. To investigate the function of osteocalcin during bone remodelling, osteocalcin-deficient mice $\left(o s c^{m l} / o s c^{m l}\right)$ were generated by simultaneously deleting both $O G 1$ and $O G 2$ using embryonic stem (ES) cell technology (Fig. 1). Heterozygous mice were phenotypically normal. Crosses between these heterozygotes produced homozygous mutant $o s c^{m l} / o s c^{m l}$ mice at predicted mendelian frequencies. Because both $O G 1$ and $O G 2$ were deleted, osteocalcin was not expressed in these mice (Fig. 1d-f). There was no ectopic expression of ORG in bone (Fig. 1d), indicating that $o s c^{m l}$ is a null allele for osteocalcin. These mice were normal at birth, viable and fertile, and had no skeletalpatterning defects and no ectopic bone formation. The expression of other NCPs such as osteopontin, matrix gla protein, and bone sialo protein was not significantly affected by the absence of osteocalcin (Fig. $1 \mathrm{~g}$ and data not shown). The ultrastructure of the bone ECM of 3- and 6-month-old wild-type and mutant animals examined by electron microscopy was identical (data not shown). 
Over time the mutant mice developed abnormalities of bone remodelling which became noticeable in 6-month-old animals. Radiographic analysis of the long bones of 6-month-old wild-type and mutant animals revealed that the mutant long bones had increased cortical thickness and density compared to wild-type littermates, consistent with an increased amount of mineralized bone matrix (Fig. 2a). In the bones of 9-month-old animals, the same features were present and were accompanied by an increase in the width of the diaphysis (Fig. $2 b$ ).

Histological analysis of 6- and 9-month-old animals showed the presence of more cancellous bone in mutant animals than in wild-type littermates (Fig. $2 c, d$ and data not shown). The width of cortical bone in 6-month-old mutant mice was increased compared with that of their wild-type littermates, reaching $150 \%$ of the wild-type width by 9 months of age $\left(o s c^{m l} / o s c^{m l}\right.$ mice,
$257 \pm 28 \mu \mathrm{m} ; \mathrm{Osc}^{+} / \mathrm{Osc}^{+}, 169 \pm 20 \mu \mathrm{m}, n=3$; Fig. $\left.2 g-j\right)$. The functional consequences of this increase in bone mass were analysed biomechanically. In 6-month-old mutant mice, a significant increase in failure load, a biomechanical indicator of bone strength $^{8}$, was observed compared with that of wildtype littermates $\left(\right.$ osc $^{m l} / o s c^{m l}$ mice, $33.79 \pm 5.41 \mathrm{~N}$; $\mathrm{Osc}^{+} / \mathrm{Osc}^{+}$, $27.08 \pm 3.25 \mathrm{~N} ; P<0.05$ ANOVA, $n=6)$. This result indicates that the increase in bone tissue had a beneficial effect on the mechanical properties of the bones.

To determine whether this increase in bone mass was due to an increase in bone formation, histomorphometry analysis was performed by double-labelling with tetracycline, a marker of the amount of newly formed bone ${ }^{9}$. At both 4.5 and 6 months of age there was a $50 \%$ increase $(P<0.05, n=4)$ in the percentage of labelled surface in mutant animals compared to wild-type

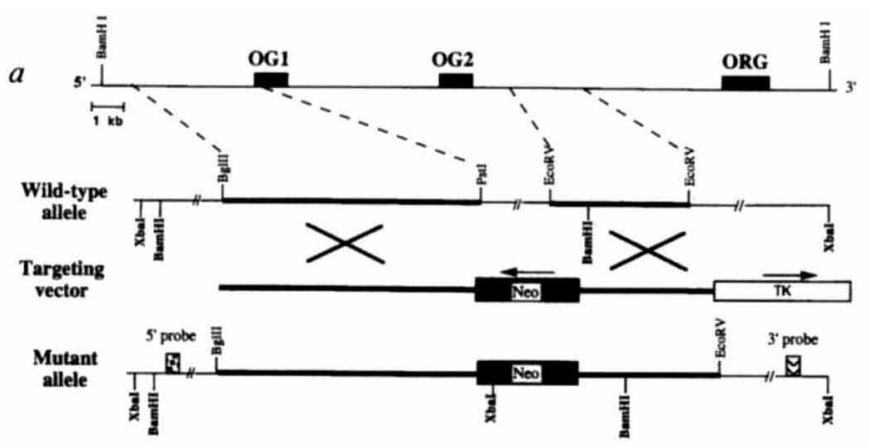

$b$

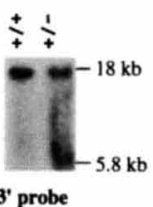

3 ' probe

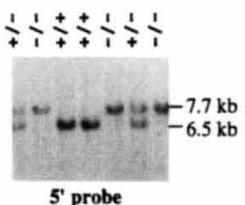

5' probe

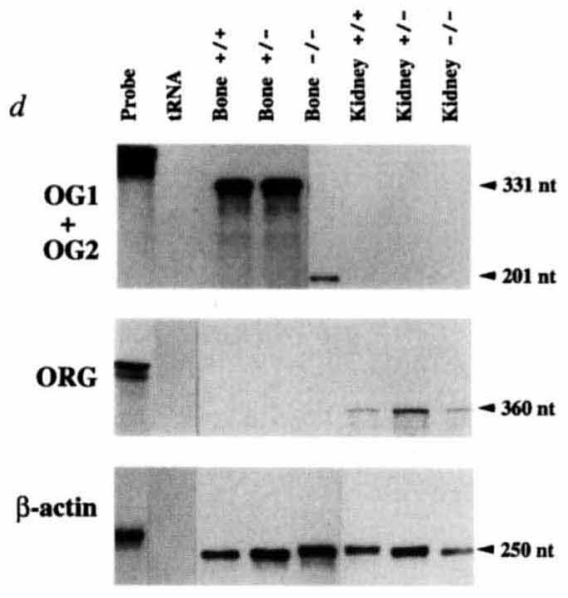

FIG. 1 Gene targeting at the osteocalcin locus. a, Representation of the expected gene replacement at the mouse Osteocalcin locus ${ }^{7}$ (Osc). Exon 4 of osteocalcin gene 1 (OG1), which codes for the mature protein, and the entire osteocalcin gene 2 (OG2) sequence were deleted, while osteocalcinrelated gene $(O R G)$ was retained. Correct targeting resulted in the replacement of the entire mature osteocalcin protein-coding sequences by the pGKNeo cassette ${ }^{1}$. The MC1-tk (thymidine kinase) expression cassette ${ }^{16}$ was used for negative selection. The $5^{\prime}$ and $3^{\prime}$ external probes used for Southern-blot analysis are shown as patterned boxes. $b$, Southern blot analysis of targeted ES cell DNA. The presence of a $5.8-\mathrm{kb}$ Xbal fragment indicates proper targeting of the Osc locus at the $3^{\prime}$ end. c, Southern blot analysis of DNA from the offspring of heterozygous matings. Genomic DNA $(5 \mu \mathrm{g})$ isolated from the tails of one litter was digested with $\mathrm{BamHI}$ and analysed with the $5^{\prime}$ probe. The presence of a single 7.7- $\mathrm{kb}$ fragment indicates a homozygous mutant $(-/-)$ genotype. $d$, RNase protection analysis of RNA from the offspring of heterozygous matings. $15 \mu \mathrm{g}$ of total RNA collected from bone or kidney was hybridized with a labelled riboprobe corresponding to mouse osteocalcin cDNA (OG1 + OG2) or to the first exon of ORG (ORG). Arrowheads denote the positions of the expected protected products. The 201-nucleotide (nt) band observed with the OG1/ OG2 probe in homozygote mutant animals corresponds to the expected protected product of the first three exons of OG1. tRNA was used as a

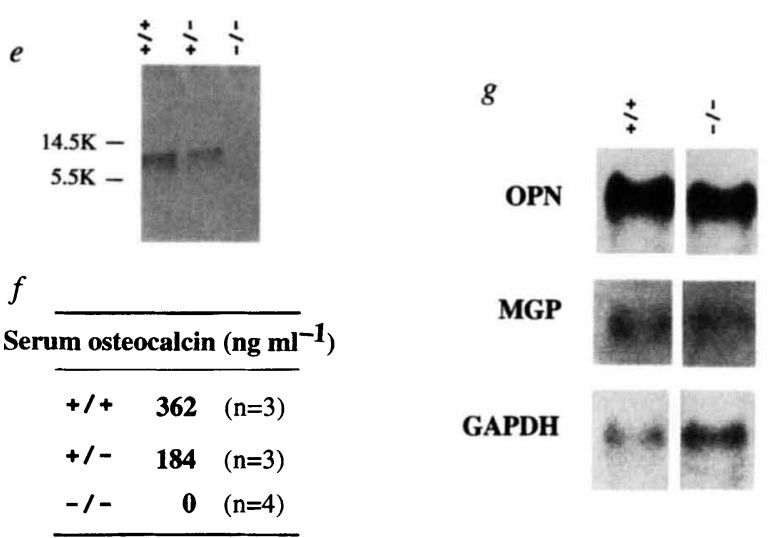

negative control. $5 \mu \mathrm{g}$ of RNA from bone and kidney was hybridized with a control $\beta$-actin riboprobe. e, Western blot analysis of protein from the bone ECM of wild-type $(+/+)$, heterozygote $(+/-)$, and homozygote mutant $(-/-)$ mice. $f$, Radioimmunoassay of serum osteocalcin in wild-type $(+/+)$, heterozygote $(+/-)$, and homozygous mutant $(-/-)$ animals. Numbers in parentheses indicate numbers of animals tested. g, Northern blot analysis of RNA from 6 -week-old wild-type $(+/+)$ and homozygote mutant $(-/-)$ mice. $15 \mu \mathrm{g}$ of total RNA from bone was hybridized with a labelled probe corresponding either to the mouse matrix gla protein $\mathrm{CDNA}^{17}$ (MGP) or to the rat osteopontin $\mathrm{CDNA}^{18}(\mathrm{OPN})$. A glyceraldehyde-3-phosphate dehydrogenase (GAPDH) probe was used to normalize the quantity of RNA in each lane.

METHODS. Culture and transfection of ES cells have been described ${ }^{19}$. Briefly, AB2.1 ES cells were transfected with $25 \mu \mathrm{g}$ linearized targeting vector per $10^{7}$ cells with a Biorad Gene Pulser and grown under double selection $^{1,16}$. Targeted ES cell clones were identified by Southern blot hybridization and were injected into C57BL/ 6 blastocysts ${ }^{20}$. Male chimaeras were mated to C57BL/6 females and their heterozygous offspring were intercrossed to generate $\mathrm{osc}^{\mathrm{m} 1} / \mathrm{osc}^{\mathrm{m} 1}$ mice. RNase protection assays were done with an RPA II kit (Ambion), following the manufacturer's instructions. Radioimmunoassay and western blot analysis were done with an antimouse osteocalcin antibody ${ }^{21}$. 
FIG. 2 Radiological and histological analysis of the bones of osc ${ }^{m 1} /$ osc $^{m 1}$ mice. $a, b, \mathrm{X}$-ray of femora of wildtype $(+/+)$ and mutant $(-/-)$ littermates of $6(a)$ and 9 months old $(b)$. Note the denser aspect and increase in cortical thickness of the long bones of mutant compared with wildtype animals. The head of the femur of the 9-monthold mutant mouse was sectioned for histological analysis in a separate experiment. $c, d$, Histological analysis of cancellous bone in 9-month-old wildtype (c) and osc $^{m 1} /$ osc $^{m 1}$ mice $(d)$. Longitudinal sections were made through the femora. Note the abundance of calcified cancellous bone surrounding the growth-plate cartilage. $e, j$, Histological analysis of cortical bones of wild-type $(e, g, i)$ and osc $^{m 1} / \mathrm{osc}^{m 1}$ mice $(f, h, j)$ of $3(e, f), 6$ $(g, h)$, or 9 months old $(i, j)$. Longitudinal sections are through the femora. Note the progressive increase in cortical thickness in the bones of mutant mice.

METHODS. Mice were killed by cervical dislocation, and tissues were fixed in fresh $4 \%$ paraformaldehyde for 10 to $24 \mathrm{~h}$. Samples were demineralized for
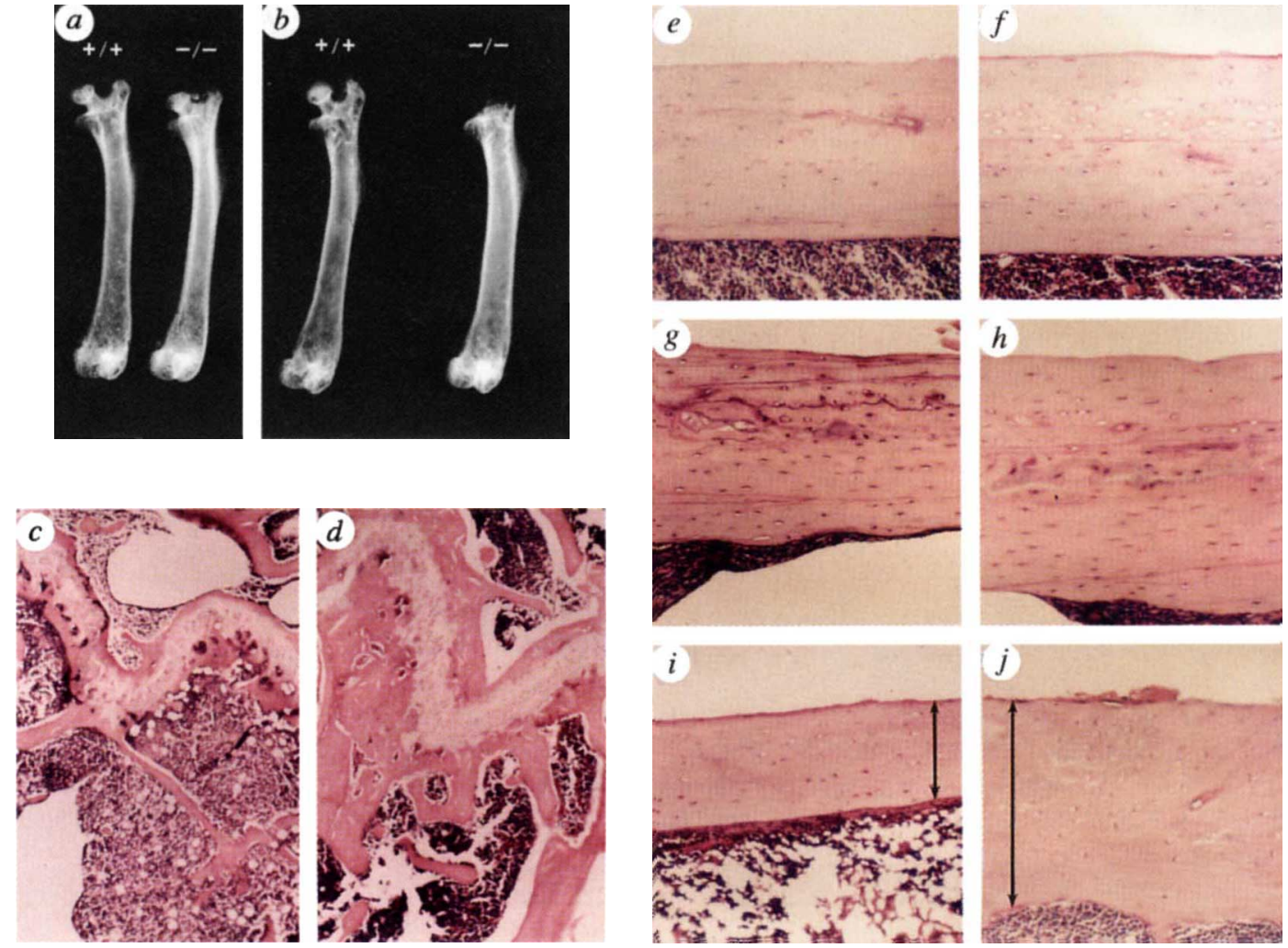

2 days in $10 \%$ formic acid, dehydrated, embedded in paraffin, sectioned at $5 \mu \mathrm{m}$ and stained with haematoxylin/eosin.
FIG. 4 In vivo analysis of bone resorption in osc $^{m 1} / \mathrm{osc}^{m 1}$ mice. 5-month-old wildtype $(+/+)$ and homozygous osc ${ }^{m 1} /$ osc $^{m 1}$ $(-/-)$ mice were sham-operated (SHAM) or ovariectomized (OVX), and killed 28 days later. a, X-ray analysis of long bones (humerus) of SHAM (left) or OVX (right) 6-month-old animals. Note the lighter aspect of the bones of the OVX mice, indicating a loss of bone mass. $b$, Histomorphometric measurements of the bone-marrow cavity area, which is significantly larger in OVX osc ${ }^{m 1} / \mathrm{osc}^{m 1}$ mice (Student's $t$-test). $c-e$, Biomechanical analysis of the quality of the femora. Yield energy is an indicator of ductility of bone specimens. Failure load is a measure of the strength of the bone, and stiffness is an indicator of the elasticity of the bone ${ }^{8}$. The decreases in yield energy, failure load, and stiffness in OVX animals indicate a bone fragility similar to that in osteoporosis. ${ }^{*} P<0.05$, $* * P<0.001, n=6$.

METHODS. Femora were tested to failure by four-point bending on an MTS servohydraulic testing machine at a constant displacement rate of $0.5 \mathrm{~mm} \mathrm{~s}^{-1}$ (ref. 8) Stiffness was calculated as the slope of the linear portion of the load-displacement curve, and yield energy was determined as the area under the loaddisplacement curve. Statistical significance was determined by one-way ANOVA with Tukey's post-hoc test for group comparison.

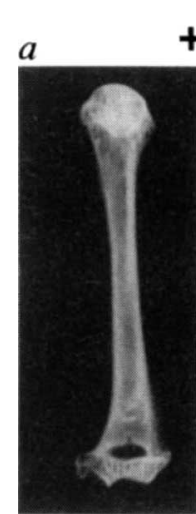

$+1+$

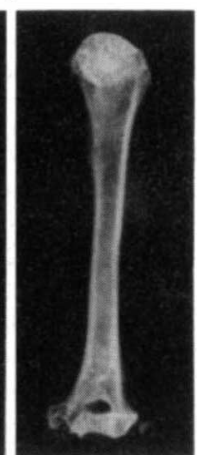

SHAM

ovX

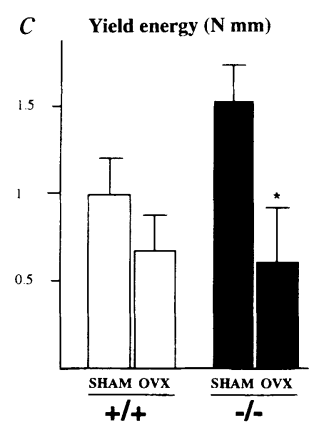

$-/-$

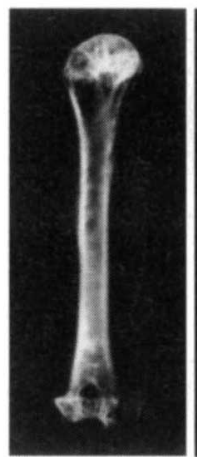

SHAM

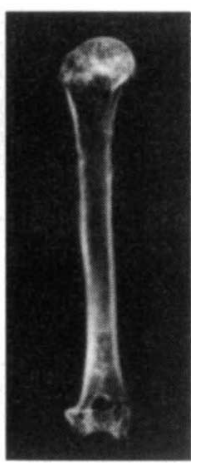

ovx $b$

\begin{tabular}{ccc}
\hline \multicolumn{3}{c}{$\begin{array}{c}\text { Bone marrow area } \\
\left(\mathbf{m m}^{2}\right)\end{array}$} \\
$+/+$ & SHAM & $\mathbf{0 . 1 6} \pm 0.01$ \\
& OVX & $\mathbf{0 . 1 8} \pm 0.01$ \\
\hline & SHAM & $\mathbf{0 . 2 3} \pm 0.01$ \\
$-/-$ & OVX & $\mathbf{0 . 2 8} \pm 0.02 *$
\end{tabular}
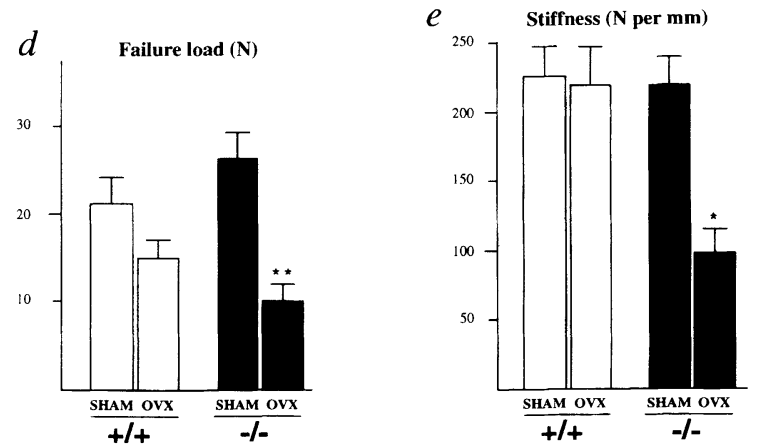


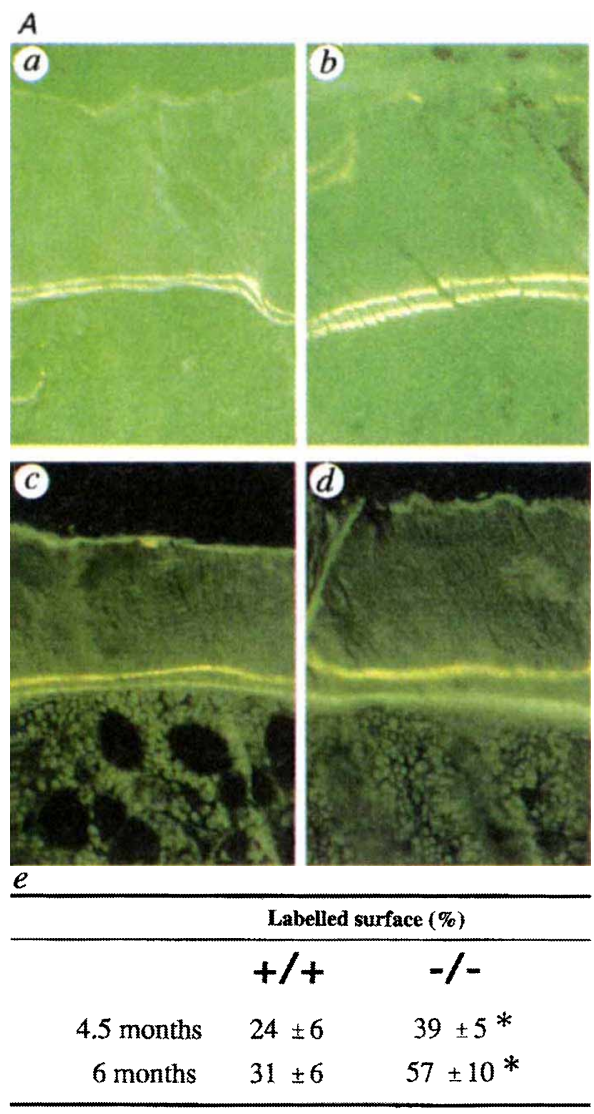

FIG. 3 In vivo analysis of bone formation in ${ }^{2} c^{m 1} / o s c^{m 1}$ mice. a, Tetracyclin/ calcein double-labelling analysis in osc ${ }^{m 1} / \operatorname{osc}^{m 1}$ mice. $a-d$, Fluorescent micrographs of the two labelled mineralization fronts in representative sections of the mid-diaphysis of the femora of wild-type $(a, c)$ and $\mathrm{osc}^{m 1} / \mathrm{osc}^{m 1}$ mice $(b, d)$ of $4.5(a, b)$ and 6 months old $(c, d)$. Note the increase in cortical thickness and in the distance between the two labelled areas, as well as the wider aspect of the labelled areas in the mutant animals, reflecting the increase in bone-matrix deposition rate. $e$, Quantification of the percentage of labelled surface in wild-type $(+/+)$ and mutant $(-/-)$ littermates. $B$, Static and dynamic histomorphometric analysis of vertebrae and femora of wild-type $(+/+)$ and homozygous osc ${ }^{m 1} /$ osc $^{m 1}$ $(-/-)$ mice. Measurement of bone-formation rates $(a, b)$ and cell surfaces (c-e) in wild-type and $\operatorname{osc}^{m 1} / \operatorname{osc}^{m 1}$ mice of 4.5 and/or 6 months old. Bars represent means \pm s.e.m. Asterisks indicate a statistically significant

littermates (Fig. $3 A$ ), indicating that the lack of osteocalcin leads to an increase in bone formation. Likewise, the cancellous and cortical bone-formation rates were significantly increased in the long bones and vertebrae of $o s c^{m 1} / o s c^{m 1}$ mice (Fig. $3 B, a$ and $b$ ). Remarkably, considering the increase in bone-formation rates, the osteoblast surface, which is a reliable indicator of the number of osteoblasts ${ }^{9,10}$, was not increased in the mutant animals (Fig. 3B, c).

Another important finding of the histomorphometry analysis was the increase in osteoclast number and surface in the bones of $o s c^{m 1} / o s c^{m 1}$ mice (Fig. $3 B, d$ and $e$ ). This raised the possibility that the osteoclasts were functioning poorly in mutant mice. To test the function of the osteoclasts in vivo, 5-month-old wild-type and mutant mice were ovariectomized. Ovariectomy, and the oestrogen depletion it creates, causes a rapid increase in bone resorption which ultimately leads to osteoporosis ${ }^{11,12}$. X-ray analysis one month after ovariectomy showed the expected slight decrease in bone density in wild-type mice ${ }^{13}$. This decrease was greater in $o s c^{m l} / o s c^{m l}$ animals (Fig. 4a). Histomorphometric analysis showed an increase in bone-marrow area, a good indicator of osteoclast function ${ }^{10,13}$, in both wild-type and mutant animals after ovariect-

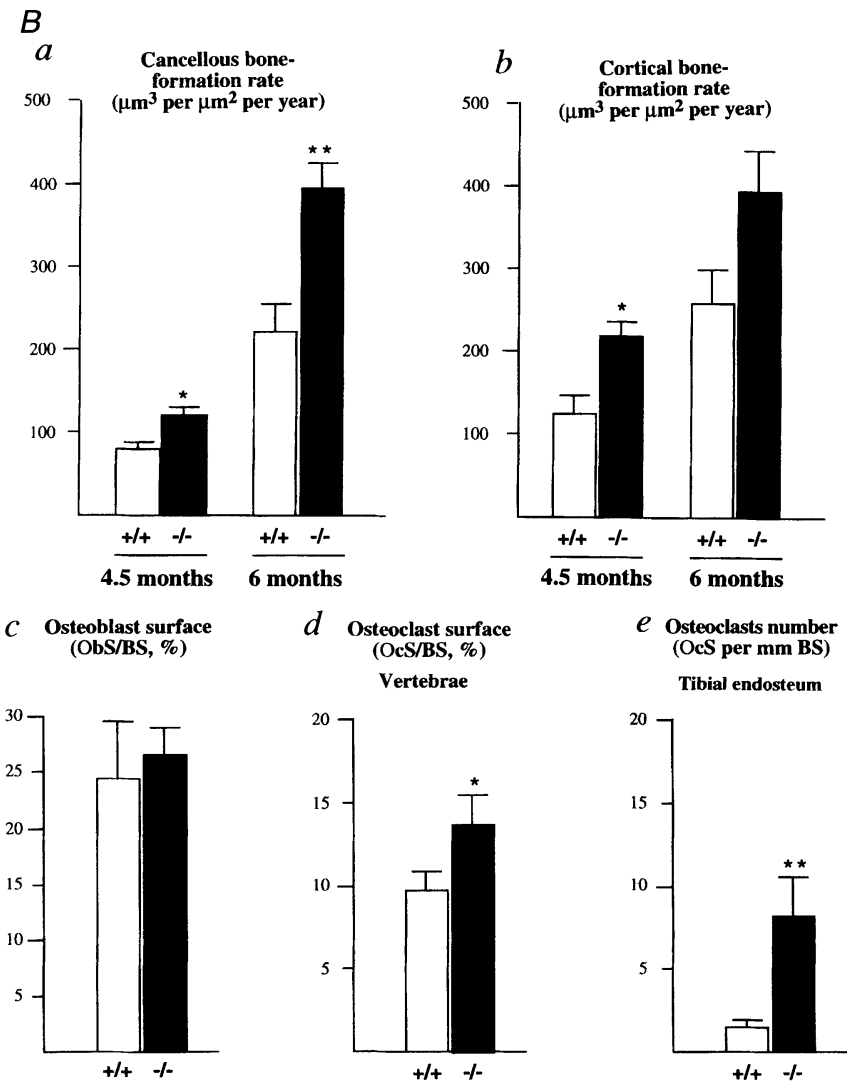

difference between wild-type and ${ }^{\circ s c^{m 1}} / o s c^{m 1}$ mice groups $\left({ }^{*} P<0.05\right.$, $\left.{ }^{* *} P<0.005\right)$. For 4.5 months, $n=4$; for 6 months, $n=7$. METHODS. Double labelling has been described ${ }^{22}$. Tetracycline injection ( $25 \mathrm{mg}$ per $\mathrm{kg}$ body weight) was followed by the same dose of calcein 10 days later. Animals were killed 2 days after the second injection, and their bones were dissected and fixed in PBS-buffered formaldehyde $(\mathrm{pH} 7.1)$. After embedding in methylmethacrylate and sectioning at $6 \mu \mathrm{m}$, a blind analysis of the unstained samples was conducted under fluorescent light. Histomorphometric parameters follow the recommended nomenclature ${ }^{10}$. Osteoblast surface was measured according to published protocols ${ }^{9}$ with the Bioquant Image Analysis System (R\&M Biometrics). Osteoclast surface was measured as the surface of tartrate-resistant acid-phosphatase-positive cells ${ }^{23-25}$. Statistical differences between groups were assessed by Student's t-test.

omy (Fig. 4b). Biomechanical studies showed that the long bones of ovariectomized $o s c^{m l} / o s c^{m l}$ mice were weaker than the bones of sham-operated animals (Fig. $4 c-e$ ). These results demonstrate that bone resorption occurs normally in $o s c^{m l} / o s c^{m 1}$ mice. Consistent with the increase in osteoclast surface in mutant mice before ovariectomy, these animals may develop a more severe osteroporosis than their wild-type littermates after oestrogen depletion.

To determine whether osteocalcin plays a role in bone mineralization, von Kossa staining was performed, and both mineral apposition rates and bone mineral contents were measured. By these criteria, wild-type and mutant bones were indistinguishable (data not shown), indicating that the absence of osteocalcin did not affect bone mineralization.

Thus, osteocalcin normally functions to limit bone formation without impairing bone resorption or mineralization. The molecular mechanism by which osteocalcin controls bone matrix deposition is unknown. The increase in bone formation rates occurs without a comparable increase in osteoblast surface, indicating that each osteoblast is laying down more matrix. This suggests that osteocalcin, like other members of the family of 
proteins to which it belongs ${ }^{14,15}$, may bind to a specific, yet to be identified, receptor to fulfil its function. The identification of osteocalcin as a negative regulator of bone formation suggests that an antagonist of osteocalcin synthesis or function, in conjunction with oestrogen replacement therapy, may be of some therapeutic use.

Received 19 March; accepted 28 May 1996.

1. Soriano, P., Montgomery, C., Geske, R. \& Bradley, A. Cell 64, 693-702 (1991)

2. Wang, Z-Q. et al. Nature 360, 741-745 (1992).

3. Grigoriadis, A. E. et al. Science 266, 443-448 (1994).

4. Hauschka, P., Lian, J., Cole, D. \& Gundberg, C. Physiol. Rev. 69, 990-1047 (1989).

5. Weinreb, M., Shinar, D. \& Rodan, G. A. J. Bone Miner. Res. 5, 831-842 (1990).

6. Boivin, G. et al. Virchows Arch. A. Path. Anat. 417, 505-512 (1990).

7. Desbois, C., Hogue, D. A. \& Karsenty, G. J. biol. Chem. 269, 1183-1190 (1994).

8. Bonadio, F. et al. Proc. natn. Acad. Sci. U.S.A. 87, 7145-7149 (1990).

9. Poli, V. et al. EMBO J. 13, 1189-1196 (1994)

10. Parfitt, A. M. et al. J. Bone Miner. Res. 2, 595-610 (1987).

11. Parfitt, A. M. et al. J. clin. Invest. 72, 1396-1409 (1983).

12. Parfitt, A. M., Riggs, B. L. \& Melton, L. J. Osteoporosis: Etiology, Diagnosis and Management. (eds Parfitt, A. M., Riggs, B. L. \& Melton, L. J.) 501 (Raven, New York, 1988)

13. Bain, S. D., Bailey, M. C., Celino, D. L., Lantry, M. M. \& Edwards, M. W. J. Bone Miner. Res. 8, 435-442 (1993)

14. Stitt, T. N. et al. Cell 80, 661-670 (1995)

15. Coughlin, S. Thromb. Haemost. 70, 184-187 (1993).

16. McMahon, A. P. \& Bradley, A. Cell 62, 1073-1085 (1990)

17. Luo, G., D'Souza, R., Hogue, D. \& Karsenty, G. J. Bone Miner. Res. 10, 325-334 (1995),

18. Oldberg, A., Franzen, A. \& Heinegard, D. Proc. natn. Acad. Sci. U.S.A. 83, 8819-8823 (1986).

19. Ramirez-Solis, R., Davis, A. \& Bradley, A. Meth. Enzym. 225, 855-878 (1993).

20. Bradley, A. Teratocarcinomas and Embryonic Stem Cells: A Practical Approach (ed. Robinson, E. J.) 113-151 (IRL, Oxford, 1987).

21. Gundberg, C., Hauschka, P., Lian, J. \& Gallop, P. M. Meth. Enzym. 107, 516-566 (1984).

22. Vignery, A. \& Baron, R. Anat. Rec. 196, 191-200 (1980)

23. Andersson, G. N. \& Marks, S. J.J. Histochem. Cytochem. 37, 115-117 (1989).

24. Boyce, B. F., Yoneda, T., Lowe, C., Soriano, P. \& Mundy, G. R. J. clin. Invest. 90, 1622-1627 (1992).

25. Jilka, R. L. et al. Science 257, 88-91 (1992).

ACKNOWLEDGEMENTS. We thank K. Hagihara for the western blot, E. Loyer and I. Schwartz for X-ray analysis, and K.-F. Tseng and A. Farias for help with the project. G.K. thanks R. Baron and A. Nanci for advice and $\mathrm{H}$. Bellen, L. Etkin, R. Gagel, S. Goldring, W. Klein and G. Mundy for critically reading the A.B. is an investigator with the Howard Hughes Medical Institute.

CORRESPONDENCE and requests for materials should be addressed to G.K. (e-mail: gkarsenty@ molgen.mda.uth.tmc.edu)

\section{Induction of a specific muscle cell type by a hedgehog-like protein in zebrafish}

\section{Peter D. Currie \& Phillip W. Ingham}

Molecular Embryology Laboratory, Imperial Cancer Research Fund, 44 Lincoln's Inn Fields, London WC2A 3PX, UK

THE notochord plays a central role in vertebrate development, acting as a signalling source that patterns the neural tube and somites $^{1-4}$. In in vitro assays, the secreted protein Sonic hedgehog mimics the inducing effects of notochord on both presomitic mesoderm and neural plate explants of amniote embryos, suggesting that both patterning activities of the notochord may be mediated by this protein in vivo ${ }^{5-8}$. In zebrafish, however, mutants with disrupted notochord development lack a specific muscle cell type, the muscle pioneers, although they retain the ability to induce neural differentiation, raising the possibility that neural tube and somite patterning may be mediated by distinct signals ${ }^{9,10}$. Here we describe a new member of the hedgehog family, echidna hedgehog, that is expressed exclusively in the notochord and has the ability to rescue the differentiation of muscle pioneer cells in mutants with no notochord. Moreover, we show that a combination of ectopic echidna hedgehog and sonic hedgehog expression induces supernumary muscle pioneers in wild-type embryos, suggesting that both signals act sequentially to pattern the developing somites.

Embryos homozygous for the zebrafish mutations no tail ( $n t l)$ and floating head ( $f(h)$ lack differentiated notochords and exhibit concomitant somite defects ${ }^{9,10}$. In both cases, somites are irregularly shaped and lack a horizontal myoseptum, a structure of the dorsoventral midline of the myotome. They also lack a specialized group of muscle cells, the muscle pioneers (MPs), which are amongst the earliest differentiating and migrating cells of the myotome ${ }^{9-12}$. MPs can easily be distinguished from other muscle cells as they express engrailed $(e n)^{11}$. In wild-type fish, between two and six MPs form directly apposed to the notochord in each somite, aligned at the level of the horizontal myoseptum ${ }^{11}$.

Both the $n t l$ and $f h$ genes encode transcription factors whose expression is principally confined to the axial mesoderm that gives rise to the notochord ${ }^{9,10}$. Thus the somite defects seen in each mutant are secondary consequences of their effects on notochord differentiation, reflecting the role of the notochord in somite patterning. Importantly, however, expression of the putative notochord-derived signal, sonic hedgehog (shh), is retained during early stages of development in $f h$ and $n t l$ embryos and, in line with this observation, induction of floorplate differentiation in the ventral neural tube occurs, to varying extents in both mutants ${ }^{10,13}$. Taken together these findings suggest that Shh activity is not sufficient for MP induction and imply the existence of some other notochord-derived MP-inducing activity.

We identified one member of the hedgehog $(h h)$ gene family cloned in zebrafish ${ }^{13}$, echidna hedgehog (ehh), which is expressed exclusively within cells of the presumptive notochord. The sequence of the ehh open reading frame reveals a high degree of sequence identity with other Hedgehog proteins (Fig. 1a). All amino-acid motifs implicated in Shh function are conserved in the Ehh protein, and like $s h h$, ehh can activate the $h h$ signalling pathway in Drosophila when misexpressed in imaginal discs (unpublished observations). In the developing zebrafish embryo, expression of ehh is first detectable somewhat later than is expression of $s h h$, at the mid-gastrula stage in cells of the axial midline ${ }^{13}$ (data not shown). Expression spreads along the midline as the axial mesoderm extends towards the animal pole (Fig. $2 a$ ), and by early somitogenesis its anterior and dorsoventral limits can be seen to coincide with that of the notochord (Fig. $2 a-c$ ). As somitogenesis continues, expression diminishes in a rostral-tocaudal progression along the length of the notochord, becoming confined to the tail notochord by the 26-somite stage (Fig. $2 e$ ) and disappearing completely by the end of somitogenesis. By comparison, shh expression is found within cells of the neural tube and notochord during somitogenesis and this expression is maintained after somitogenesis is completed (Fig. $2 d, f$ ).

Unlike shh, expression of $e h h$ cannot be detected at any stage in either $n t l$ or $f h$ homozygous embryos (Fig. $2 g-j$, and data not shown). Thus absence of MPs correlates with absence of ehh expression, suggesting that $e h h$ may be required for MP induction. To test this, we assayed the activity of $e h h$ using the same overexpression methods used previously to analyse $s h$ function $^{13}$. Injection of shh sense messenger RNA into 1-2-cell-stage embryos produces a number of morphological abnormalities, notably a disruption of eye development, but has no obvious morphological effect on the development of the somites ${ }^{13-15}$ (80\%, $n=96$; data not shown). Similar effects are induced by ectopic expression of another hedgehog-family gene, tiggy-winkle hedgehog (twhh) $(67 \%, n=45)^{14}$, that is also expressed along the midline of the developing embryo ${ }^{14}$. By contrast, ehh sense mRNA fails to produce any morphologically detectable phenotype when injected under identical conditions $(n=162)$, or even when injected at 5 times higher concentrations $(n=45)$. To test the possibility that this lack of effect reflects an inefficient processing of the Ehh protein, we generated a truncated mRNA that encodes only the predicted mature amino-terminal fragment of Ehh. Injection of this mRNA under identical conditions similarly resulted in no morphological defects $(n=53)$. However, when 